\title{
Oral Hygiene and Periodontal Health Status of Urban Population of Kathmandu District: A Pilot Study
}

\author{
Dr. Rosina Bhattarai, ${ }^{1}$ Dr. Sunita Khanal, ${ }^{2}$ Dr. G. Nagaraja Rao, ${ }^{3}$ \\ Dr. Bhageshwar Dhami, ${ }^{4}$ Dr. Sujaya Gupta ${ }^{5}$ \\ 1,2Resident, ${ }^{3}$ Professor, Department of Community Dentistry \\ ${ }^{4}$ Assistant Professor, ${ }^{5}$ Lecturer, Department of Periodontics \\ Kantipur Dental College, Kathmandu, Nepal
}

\begin{abstract}
Background: Healthy teeth, their supporting structures and gingiva play an important role in oral health. Gingivitis progresses to periodontitis in a phased manner causing continuous deterioration. In severe cases, removal of the tooth becomes inevitable. Hence, if gingivitis and periodontitis can be identified and treated earlier, tooth loss can be minimized.

Aim: To assess the status of oral hygiene, gingival and periodontal health of Urban population of Kathmandu district.

Materials and methods: Data on cross-sectional study of 252 individuals was collected using pre-designed survey form utilizing Gingival Index, Oral Hygiene Index-Simplified and Community Periodontal Index. Collected data was analyzed using SPSS version 20.

Results: An urban population of 126 males and 126 females were examined in Kathmandu for this survey. In this study, 55.6\% were of agegroup 20-39 years while $44.4 \%$ were of $40-60$ years, $35.31 \%$ and $54.76 \%$ of individuals had good and fair oral hygiene respectively \& $49.20 \%$ of them had deposition of calculus and $25 \%$ had loss of attachment of $4-5 \mathrm{~mm}$. Only $16.6 \%$ were having healthy gingiva whereas $52.38 \%$ had mild and $26.5 \%$ had moderate gingivitis. Statistically significant results of all above are seen with advancement of age ( $p<0.05$ ).

Conclusion: Results show that gingival and periodontal diseases are widely distributed in urban population. Hence, appropriate preventive and periodic therapies should be employed.

Key Words: CPI, oral hygiene status, urban
\end{abstract}

\section{INTRODUCTION}

Oral diseases are one of the most common of the chronic diseases and pose an important public health problem because of their prevalence, their impact on individuals and society and the expense of their treatment. ${ }^{1}$ However, oral health is often undervalued in terms of its effects on patient's health and nutrition. This compartmentalization involved in viewing mouth separately from the rest of the body must cease because oral health affects general health by causing considerable pain and suffering and by changing the way in which people eat, speak as well as their quality of life and well-being. ${ }^{2,3}$

\section{Correspondence:}

Dr. Rosina Bhattarai

Department of Community Dentistry, Kantipur Dental College, Kathmandu, Nepal

email: rosinabhattarai@gmail.com

\section{Citation}

Bhattarai R, Khanal S, Rao GN, Dhami B, Gupta S. Oral hygiene and periodontal health status of urban population of Kathmandu district: a pilot study. J Nep Soc Perio Oral Implantol. 2017;1:12-6.
Healthy teeth, their supporting structures as well as gingiva play an important role in oral health. Dental plaque, a diverse microbial community found on the tooth surface embedded in a matrix of polymers of bacterial and salivary origin, widely affects the periodontium. ${ }^{4}$ Gingivitis progresses to periodontitis which is one of the major cause for which people seek removal of tooth. ${ }^{5}$ Hence, if gingivitis and periodontitis can be identified earlier, loss of damage to the supporting structure can also minimized. The aim of present study was to assess the status of oral hygiene, gingival and periodontal health of Urban population of Kathmandu district.

\section{MATERIALS AND METHODS}

Study design: A cross-sectional study among 252 individuals was carried out using Community Periodontal Index (CPI), Loe and Silness Gingival Index (GI) and measuring Loss of Attachment (LOA). Additionally Oral Hygiene Index Simplified (OHI-S) by John C. Greene and Jack R. Vermillion was also taken. Sample size was calculated by convenience sampling method using mean prevalence of periodontitis 
in adults of age group 35-44 years and more than 50 years, according to Nepal National Pathfinder Survey, 2004.

Ethical approval was obtained from Institutional Review Committee of Kantipur Dental College. The participation in the study was voluntary and informed consent was obtained. The details of the participants remained anonymous.

Data was collected among the patients visiting Kantipur Dental College and those visiting community camps organized within the urban areas of Kathmandu district. Oral health examination was carried out using Community Periodontal Index of Treatment Needs probe, explorer and mouth mirrors. Personal interview was conducted to collect information regarding oral hygiene measures, dietary habits and habits such as smoking and tobacco chewing.

Statistical analysis: Assessing the demographic characteristics and personal habits with CPI, the participants were thus categorized into Code 0 (Healthy) as healthy periodontium, Codes 1 (Bleeding on probing) and 2 (Calculus detected during probing) into gingivitis and codes 3 (Pocket of 4-5 mm depth) and 4 (Pocket $6 \mathrm{~mm}$ or more) into periodontitis. The results were analyzed using SPSS version 20. Descriptive statistics were obtained and chi-square test was done. $p<0.05$ was considered statistically significant.

\section{RESULTS}

A total number of 252 people were examined out of which there were 126 males and 126 females. The participants were categorized into two groups based on their age. First group comprised of those of age group 20-39 years while second group comprised of those of age group 40-60 years. Results of the study and clinical observations support that the people affected by systemic diseases are less resistant to local traumatic influences around periodontal tissues. $37.14 \%$ of hypertensive patients showed calculus, $40 \%$ showed pocket of depth 4-5 mm, 37.14\% showed LOA of 4-5 mm ( $p=0.00)$ showing statistical significance. Similarly, in diabetic patients it was found that $38.46 \%$ had calculus, $46.15 \%$ had pocket of depth 4-5 mm and $38.46 \%$ had LOA of $4-5 \mathrm{~mm}$ which was also significant $(p=0.00) .42 \%$ of hypertensive patient exhibited mild gingivitis and $40 \%$ had moderate gingivitis. Similarly, in diabetic patients, $69.23 \%$ and $15.38 \%$ had mild and moderate gingivitis respectively $(p=0.005)$.

Out of total people examined, $65.5 \%$ had visited a dentist before and $98.8 \%$ used toothbrush and toothpaste as their oral hygiene aids. $18.3 \%$ of the total participants were smokers. Also individuals were categorized based on their Body Mass Index (BMI). 4.8\% of them were underweight, $67.1 \%$ normal weight, $23.8 \%$ overweight and $4.4 \%$ obese. However, no statistical significance was found with relation to BMI and CPI ( $p=0.785)$, LOA $(p=0.915)$ and OHI-S $(p=0.733)$.

Out of the total people examined, 54.8\% had fair, 35.3\% had good and $8.7 \%$ had poor oral hygiene. Also, $52.4 \%$ of them showed mild gingivitis, $26.6 \%$ showed moderate gingivitis while $4 \%$ showed severe gingivitis. $49.2 \%$ of them had calculus detected during probing. 25\% and 5.6\% had LOA of 4-5 $\mathrm{mm}$ and 6-8 $\mathrm{mm}$ respectively. $42.14 \%$ of $20-39$ year olds had good oral hygiene while $53.57 \%$ of those of same age group had fair oral hygiene. Similarly, $26.78 \%$ of those of

Table 1: Relationship between demographic characteristics and personal habits with periodontal health among participants

\begin{tabular}{|c|c|c|c|c|c|c|}
\hline \multirow{2}{*}{\multicolumn{2}{|c|}{ Characteristics }} & \multicolumn{4}{|c|}{ Periodontal health } & \multirow{2}{*}{$p$ value } \\
\hline & & \multirow{2}{*}{$\begin{array}{c}\text { Healthy n(\%) } \\
1(1.87)\end{array}$} & \multirow{2}{*}{$\begin{array}{c}\text { Gingivitis n(\%) } \\
22(41.50)\end{array}$} & \multirow{2}{*}{$\begin{array}{c}\text { Periodontitis } \mathbf{n}(\%) \\
27(50.94)\end{array}$} & \multirow[t]{2}{*}{ Total } & \\
\hline$\Xi$ & Illiterate & & & & & \multirow{3}{*}{0.00} \\
\hline స్ర & School level & $2(2.12)$ & $57(60.63)$ & $32(34.04)$ & 94(96.79) & \\
\hline 포 & Collegiate level & $13(12.38)$ & $77(73.33)$ & 14(13.33) & 105(99.04) & \\
\hline \multirow{2}{*}{ 营: : } & Yes & $11(6.66)$ & $102(61.81)$ & $46(27.87)$ & 165(96.34) & \multirow{2}{*}{0.67} \\
\hline & No & $5(5.74)$ & $54(62.06)$ & $27(31.03)$ & 87(98.83) & \\
\hline \multirow{2}{*}{ 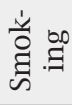 } & Yes & $0(0)$ & $30(65.21)$ & $14(30.43)$ & 46(95.64) & \multirow{2}{*}{0.23} \\
\hline & No & $16(7.76)$ & 126(61.16) & $59(28.64)$ & 206(97.56) & \\
\hline \multirow{2}{*}{ 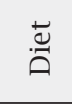 } & Vegetarian & $0(0)$ & 13(59.09) & $8(36.36)$ & 22(95.45) & \multirow{2}{*}{0.51} \\
\hline & Mixed & 16(6.95) & $143(62.17)$ & $65(28.26)$ & 230(97.38) & \\
\hline \multirow{4}{*}{$\sum_{\infty}^{E}$} & Underweight & $0(0)$ & 11(91.66) & $1(8.33)$ & 12(99.99) & \multirow{4}{*}{0.66} \\
\hline & Normal & 13(7.69) & 101(59.76) & $50(29.58)$ & 169(97.03) & \\
\hline & Overweight & $3(5)$ & $37(61.66)$ & $18(30)$ & 60(96.66) & \\
\hline & Obese & $0(0)$ & $7(63.63)$ & $4(36.36)$ & 11(99.99) & \\
\hline
\end{tabular}


40-60 years age group had good oral hygiene while 56.25\% showed fair and $14.28 \%$ showed poor oral hygiene. (Table 2) $12.14 \%$ of those belonging to age group 20-39 years showed LOA of 4-5 mm and 57.14\%showed presence of calculus while $41.07 \%$ of those of age group 40-60 years showed LOA of 4-5 $\mathrm{mm}$ and $39.28 \%$ showed presence of calculus. (Table 3 and 4) Among the 20-39 year olds $62.14 \%$ had mild while
16.42\% had moderate gingivitis while among 40-60 year olds, 40.17\% had mild and 39.28\% had moderate gingivitis. (Table

5) Statistical significance with advancing age was seen with respect to OHI-S ( $p=0.002)$ and CPI, LOA and GI $(p=0.000)$.

Calculus and pocket of depth $4-5 \mathrm{~mm}$ was seen in $49.20 \%$ and $26.98 \%$ in males respectively and $49.20 \%$ and $27.77 \%$ in females respectively. No statistical significance was seen in

Table 2: Table showing age wise distribution of OHI-S

\begin{tabular}{|c|c|c|c|c|c|}
\hline \multirow[b]{2}{*}{ Age } & \multicolumn{4}{|c|}{ OHI-S } & \multirow[b]{2}{*}{$p$ value } \\
\hline & $\begin{array}{c}\text { Good } \\
\%\end{array}$ & $\begin{array}{c}\text { Fair } \\
\%\end{array}$ & $\begin{array}{c}\text { Poor } \\
\%\end{array}$ & $\begin{array}{c}\text { Not recorded } \\
\%\end{array}$ & \\
\hline \multirow{2}{*}{ 20-39 years } & 59 & 75 & 6 & 0 & 140 \\
\hline & $42.14 \%$ & $53.57 \%$ & $4.28 \%$ & $0 \%$ & $100 \%$ \\
\hline \multirow{2}{*}{ 40-60 years } & 30 & 63 & 16 & 3 & 112 \\
\hline & $26.78 \%$ & $56.25 \%$ & $14.28 \%$ & $2.67 \%$ & $100 \%$ \\
\hline Total & 89 & 138 & 22 & 3 & 252 \\
\hline
\end{tabular}

$p$ value $=0.002$

Table 3: Table showing age wise distribution of CPI

\begin{tabular}{|c|c|c|c|c|c|c|c|}
\hline \multirow[b]{2}{*}{ Age } & \multicolumn{6}{|c|}{ CPI } & \multirow[b]{2}{*}{ Total } \\
\hline & Healthy \% & BOP \% & Calculus \% & $\begin{array}{c}\text { Pocket } \\
4-5 \mathrm{~mm} \%\end{array}$ & $\begin{array}{l}\text { Pocket } 6 \mathrm{~mm} \\
\text { or more } \%\end{array}$ & Excluded \% & \\
\hline \multirow{2}{*}{ 20-39 years } & 13 & 23 & 80 & 22 & 1 & 1 & 140 \\
\hline & $9.28 \%$ & $16.42 \%$ & $57.14 \%$ & $15.71 \%$ & $0.71 \%$ & $0.71 \%$ & $100 \%$ \\
\hline \multirow{2}{*}{ 40-60 years } & 3 & 9 & 44 & 47 & 3 & 6 & 112 \\
\hline & $2.67 \%$ & $8.03 \%$ & $39.28 \%$ & $41.96 \%$ & $2.67 \%$ & $5.35 \%$ & $100 \%$ \\
\hline Total & 16 & 32 & 124 & 69 & 4 & 2 & 252 \\
\hline
\end{tabular}

$p$ value $=0.000$

Table 4: Table showing age wise distribution of LOA

\begin{tabular}{|c|c|c|c|c|c|c|c|}
\hline \multirow[b]{2}{*}{ Age } & \multicolumn{6}{|c|}{ CPI } & \multirow[b]{2}{*}{ Total } \\
\hline & $\underset{\%}{0-3 m m}$ & $\underset{\%}{4-5 \mathrm{~mm}}$ & $\underset{\%}{6-8 m m}$ & $9-11 \mathrm{~mm}$ & $\begin{array}{c}\text { Excluded } \\
\%\end{array}$ & $\begin{array}{c}\text { Not recorded } \\
\%\end{array}$ & \\
\hline \multirow{2}{*}{ 20-39 years } & 120 & 17 & 2 & 0 & 0 & 1 & 140 \\
\hline & $85.71 \%$ & $12.14 \%$ & $1.42 \%$ & $0 \%$ & $0 \%$ & $0.71 \%$ & $100 \%$ \\
\hline \multirow{2}{*}{$40-60$ years } & 46 & 46 & 12 & 2 & 2 & 4 & 112 \\
\hline & $41.07 \%$ & $41.07 \%$ & $10.71 \%$ & $1.78 \%$ & $1.78 \%$ & $3.57 \%$ & $100 \%$ \\
\hline Total & 166 & 63 & 14 & 2 & 2 & 5 & 252 \\
\hline
\end{tabular}

$p$ value $=0.000$

Table 5: Table showing age wise distribution of Gingival Index

\begin{tabular}{|c|c|c|c|c|c|c|}
\hline \multirow[b]{2}{*}{ Age } & \multicolumn{5}{|c|}{ CPI } & \multirow[b]{2}{*}{ Total } \\
\hline & $\begin{array}{c}\text { Normal gingiva } \\
\%\end{array}$ & $\begin{array}{l}\text { Mild } \\
\%\end{array}$ & $\begin{array}{c}\text { Moderate } \\
\%\end{array}$ & $\begin{array}{c}\text { Severe } \\
\%\end{array}$ & $\begin{array}{c}\text { Not recorded } \\
\%\end{array}$ & \\
\hline \multirow{2}{*}{ 20-39 years } & 27 & 87 & 23 & 3 & 0 & 140 \\
\hline & $19.28 \%$ & $62.14 \%$ & $16.42 \%$ & $2.14 \%$ & $0 \%$ & $100 \%$ \\
\hline \multirow{2}{*}{ 40-60 years } & 15 & 45 & 44 & 7 & 1 & 112 \\
\hline & $13.39 \%$ & $40.17 \%$ & $39.28 \%$ & $6.25 \%$ & $0.89 \%$ & $100 \%$ \\
\hline Total & 42 & 132 & 67 & 10 & 1 & 252 \\
\hline
\end{tabular}

$p$ value $=0.000$ 
terms of periodontal health status and sex $(p=0.858)$. Also, statistically significant results were not seen for gender with LOA ( $p=0.527)$, OHI-S $(p=0.490)$ and GI $(p=0.590)$.

\section{DISCUSSION}

National Pathfinder Survey of Nepal as reported by Yee and Mishra summarizes that $58.2 \%$ of $5-6$ year olds, $62.8 \%$ of 12 13 year olds and $61 \%$ of $15-16$ year olds showed gingivitis and calculus. In addition to that approximately $31 \%$ of Nepalese adults of age group 35-44 years had developed deep periodontal pockets. This puts Nepal into $15 \%$ of the countries in the world with this age group bearing deep periodontal pockets. ${ }^{6}$

Kumar et al. ${ }^{7}$ carried out a study to find out the relationship between BMI and periodontal health status in Kesariyaji, India where the overall prevalence of gingival disease was 98.2\% where CPI scores 1 and 2 (bleeding and calculus) were more widespread whereas deep periodontal pockets were seen in $1.8 \%$ of the subjects. Significant difference for periodontal health between age groups is seen similar to this study.Many studies have proposed that an increased BMI may be a potential risk factor for periodontitis; however, our study showed no such association. According to Philip et al. ${ }^{5}$, out of 303 people examined among tribal population in Nilgiris, $75.2 \%$ of the total population had presence of calculus, $15.8 \%$ had periodontal pocket of $4-5 \mathrm{~mm}$ and $18.5 \%$ of total population had LOA of 4-5 mm.

Study conducted in Germany by Holtfreter et al. ${ }^{8}$ showed LOA of $\geq 3 \mathrm{~mm}$ in $95.6 \%$ and $\geq 5 \mathrm{~mm}$ in $62.4 \%$ which is more as compared to current study which showed $65.87 \%$ and $31.34 \%$ respectively. Also, males had significantly higher prevalence than females while in this study no variation with regards to sex was seen. Study by Darby et al. ${ }^{9}$ on adults of Epping, Victoria for a year also showed as subjects advance in age, there is increase in CPI scores for both males and females. According to Umoh et al. ${ }^{10}$, on a study conducted among adult driver males in Nigeria, 9.2\% had normal periodontium, $75.4 \%$ had gingivitis and $15.4 \%$ had periodontitis. Relationship between age distribution and periodontal health showed older age group had more gingivitis and periodontitis than younger counterpart similar to this study as well as study by Kumar et al. ${ }^{7}$ Also, participants with low level of education had higher prevalence of gingivitis and periodontitis. Therefore, these results were comparable to the association of increasing age and educational level with these diseases in this study. Study by Cassia et al. ${ }^{11}$ on factors related to periodontal disease in a rural population, it was found that the prevalence of periodontitis increased with age. Also, prevalence of periodontitis was two times higher when compared to nonsmokers in contrast to current study while no association was seen between hypertension and periodontitis. Mathur et al. ${ }^{12}$ found out poor oral hygiene observed in $50.2 \%$ of the adolescents where there was a socioeconomic gradient in poor oral hygiene with higher prevalence observed at each level of deprivation.

The magnitude of periodontitis prevalence and oral hygiene status noted in the present study was surprising, considering that it concerned with adults of good income and lifestyle and residents of urban areas with adequate provision and accessibility to oral health care despite increase in clinic attendance similar to study by Mohd-Dom et al. ${ }^{13}$ in Malaysia.

\section{CONCLUSION}

The study shows that the rising periodontal treatment needs in the population has not been met. Though there is an upward trend in clinic attendance and increase in hospital facilities in urban areas, the analysis shows that there is a need to give more attention to periodontal diseases. Also, there is a need to further evaluate existing public health promotion strategies. Also, to maintain ideal oral hygiene status and periodontal health in this population, appropriate preventive and periodic periodontal therapies should be provided. Special emphasis on health education and motivation play a major role in bringing down the prevalence of periodontal diseases in this group.

\section{ACKNOWLEDGEMENT}

We would like to thank Dr. Sujita Shrestha, Kantipur Dental College for her constant guidance and support. 


\section{REFERENCES}

1. Bhagat TK, Shrestha A, Yadav TN. Comparison of oral hygiene status among 6-14 year old students of public and private schools of Rajbiraj, Saptari, Nepal. J Coll Med Sci. 2015;10(1):17-21.

2. Magzoub A, Tawfig N, Satti A, Gobara B. Periodontal health status and periodontal treatment needs of prisoners in two jails in Khartoum State. Int J Dentistry Oral Sci. 2016;3(4):233-8.

3. Nethravathi TD, Joshipura V, Venugopal S, Subbaiah SK, Jagadeesh KN, Apparaju V. A comparative assessment of periodontal status and treatment needs among population in Tumkur district using CPITN: An epidemiological study. J Adv Clin Res Insights. 2015;2(3):1.

4. Gopalakrishnan S, Jayakumar P, Shankarram V. Prevalence Of Gingivitis And Periodontitis In Mugappair Population-Chennai, Tamilnadu. Int J Contemp Dent Med Rev. 2012;2(6):83-8.

5. Philip B, Chithresan K, Vijayaragavan VS, Maradi A. Prevalence of periodontal diseases among the adult tribal population in Nilgiris-an epidemiological study. Int J Public Health Dent. 2013;4(1):8-12.

6. Yee R, Mishra P. Nepal oral National Pathfinder Survey 2004. Int Dent J. 2006;56(4):196-202.

7. Kumar S, Dagli RJ, Dhanni C, Duraiswamy P. Relationship of body mass index with periodontal health status of green marble mine laborers in Kesariyaji, India. Braz Oral Res. 2009;23(4):365-9.

8. Holtfreter B, Kocher T, Hoffmann T, Desvarieux M, Micheelis W. Prevalence of periodontal disease and treatment demands based on a German dental survey (DMS IV). J Clin Periodontol. 2010;37(3):211-9.

9. Darby I, Phan L, Post M. Periodontal health of dental clients in a community health setting. Aust Dent J. 2012;57(4):486-92.

10. Umoh AO, Azodo CC. Prevalence of gingivitis and periodontitis in an adult male population in Nigeria. Niger J Basic Clin Sci. 2012;9(2):65.

11. Macêdo TC, Costa MD, Gomes-Filho IS, Vianna MI, Santos CT. Factors related to periodontal disease in a rural population. Braz Oral Res. 2006;20(3):257-62.

12. Mathur MR, Tsakos G, Parmar P, Millett CJ, Watt RG. Socioeconomic inequalities and determinants of oral hygiene status among Urban Indian adolescents. Community Dent Oral Epidemiol. 2016;44:248-54.

13. Mohd-Dom TN, Abdul-Muttalib K, Ayob R, Lan YS, Mohd-Asadi AS, Abdul-Manaf MR, Aljunid SM. Periodontal status and provision of periodontal services in Malaysia: trends and way forward. J Public Health Med. 2013;13(2):38-47.

14. Dye BA, Selwitz RH. The relationship between selected measures of periodontal status and demographic and behavioural risk factors. J Clin Periodontal. 2005;32(7):798-808. 